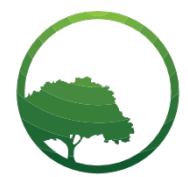

Research in Business \& Social Science

IJRBS VOL 8 NO 5 ISSN: 2147-4478

\title{
Effect of developmental efficacy on leadership development
}

\author{
Emmanuel Mango ${ }^{a^{*}}$, Jeremiah Koshal $^{b}$, Caren Ouma ${ }^{c}$ \\ ${ }^{a, b, c}$ Chandaria School of Business, United States International University, P.O. Box 14634 - 00800, Nairobi, Kenya
}

\begin{tabular}{l} 
A R T I C L E IN F O \\
\hline Article history: \\
Received 16 July 19 \\
Received in revised form 30 July 19 \\
Accepted 05 August 19 \\
\hline Keywords: \\
Leadership Development \\
Developmental Efficacy \\
Leadership \\
Leader Developmental Readiness \\
JEL Classification: \\
O15 \\
P36
\end{tabular}

\begin{abstract}
A B S T R A C T
The study investigates the effect of developmental efficacy (one of the elements of leader developmental readiness) on leadership development. The study was conducted among MBA students within private universities in Kenya. Data was collected through a validated instrument and correlation, one-way ANOVA, and regression analyses were performed. The results revealed that developmental efficacy significantly affects leadership development, $F(1,286)=79.803, p<001$, also developmental potency accounts for 21.8 percent of the variations in leadership development. The study implies that leadership developers ought to help leadership learners to gain higher developmental efficacy before or during the developmental program, for them to benefit fully from the leadership developmental interventions.
\end{abstract}

\section{Introduction}

A lot of effort and resources are invested in leadership development in organizations around the world. The problem is that the more resources are deployed towards leadership development, the more complaints about the outcomes of leadership development programs grow louder. The demand for well-developed leaders is fueled by the critical role that leaders play in running of companies. Organizations fail or succeed due to the weaknesses or the strength of organizational leadership respectively. Leadership development is central in improving the quality and the number of leaders. Development Dimensions International [DDI] (2015) argues that the average quality of leadership goes up by 20 percent for organizations that get their leadership development right. At the same time, organizations can fill 26 percent of their critical positions immediately. In addition, organizations with effective leadership development mechanism outperform those who do not have effective leadership development mechanism by 2.3 times on the financial metrics. The challenge is that the current leadership development is not yielding desired results.

Studies on the length of leadership development programs, the theoretical framework for leadership development, the content and effective delivery of leadership development programs have been conducted and the results have been implemented. Notwithstanding the research and its implementation, the quality of leadership development is still in question. The widespread search for effective leaders coupled with constant complains about the quality of leaders who have undergone leadership development is a clears indicator that there is a missing element in leadership development. Recent developments in the field of leadership, and particularly leadership development point to the observation that effective development of leaders encompasses: leader developmental readiness, developmental interventions and reflection, but leader developmental readiness is largely ignored by both leadership researchers and practitioners. One of the key elements of leader developmental readiness is developmental efficacy, hence this study establishes the effect of developmental efficacy on leadership development. The study was conducted among MBA students within private

\footnotetext{
* Corresponding author. Tel: +254-730-116000/300 ORCID ID: 0000-0002-6638-0574 Peer review under responsibility of Bussecon International Academy. (C) 2019 Bussecon International. Hosting by SSBFNET- Center for Strategic Studies in Business \& Finance. All rights reserved. https://doi.org/10.20525/ijrbs.v8i5.315
} 
universities in Kenya. For the text and organization of the study, there are five key sections including introduction, literature review, methodology, results and discussion and the conclusion.

\section{Literature Review}

\section{Leadership development}

Despite the huge demand for effective leaders and the recognition that leadership development can supply the number of effective leaders needed, leadership development largely remains ineffective. Many industry reports and academic researches show that many leaders who have invested in leadership development are dissatisfied with the results of leadership development interventions (Ardichvili, Dag \& Manderscheid, 2016). While 85 percent of the organizations surveyed by University of North Carolina [UNC] (2014), acknowledge the urgent need to accelerate leadership development, only $40 \%$ of the senior leaders surveyed believe that the leaders in their pipelines are likely to be prepared for future business needs. Another study by Development Dimensions International [DDI] (2015) revealed that only $15 \%$ of 2,031 organizations studied in 48 countries are confident of their leadership bench, while only $25 \%$ of $1,528 \mathrm{HR}$ professionals are confident with the quality of leaders in their organization. Finally only $37 \%$ of 13,124 leaders surveyed graded their organization's leadership development initiatives as effective. There is huge demand for effective leaders globally. Deloitte Consulting LLP and Bersin [Deloitte] (2014) observed that shortage of leaders is one of the critical challenges to growth for companies around the world. Kenya is one of the countries with a huge demand for effective leaders, for example, Kenya's education sector which has experienced unprecedented growth does not have well-prepared leaders, ready to fill the positions that have been created by the expansion (Mathooko \& Ogutu, 2015). Asuga, Eacott \& Scevak (2015) call for an urgent development of effective leaders to serve the education sector and other sectors within the expanding Kenyan economy.

The dire leadership development situation needs a fresh look, Snook, Nohria and Khurana (2012) assert that leadership development does not only comprise of developmental interventions, but it also involves reflection and leader developmental readiness. The latter has been largely ignored both in research and practice (Nah \& Wan, 2010; Hannah \& Avolio, 2010; Reichard \& Walker, 2016). This study rectifies the gap in literature and hopefully influences the practice of leadership development for better. The present study examines the effect of developmental efficacy (one of the five key elements of leader developmental readiness) on leadership development.

\section{Developmental efficacy}

Avolio and Hannah (2009) postulates that developmental efficacy affects leadership development, since it is the "leader's judgment regarding whether he or she can develop a specific ability or skill to employ in a certain leadership context" (p.285). If the judgement of one's ability to acquire leadership knowledge and skills is positive, the individual will be highly motivated to and confident that he/she will learn leadership, the judgment will prompt learning related behaviour. "How one views self predicts the subsequent growth and development" (Bong \& Skaalvik, 2003). According to Murphy and Johnson (2016), as we as Reichard, Walker, Putter, Middleton \& Johnson (2016), efficacy is one's beliefs or confidence in one's own capabilities to learn skills or gain knowledge. Avolio and Hannah (2008) contend that developmental efficacy is the segment of self-efficacy that is responsible for learning, however, the terms are used interchangeably, including in this study. Self-efficacy is the beliefs in one's abilities to organize and implement a course of actions in order to obtain the desired goals or one's convictions and expectation of what they can do about a specific task.

One's judgement of their capabilities determines the choices they make, including the choice to take up leadership development; it sustains one during the action period (Beverborg, Sleegers, Endedijk \& Veen, 2017). Also, self-efficacy and academic performance are significantly related (Dunbar, Dingel, Dame, Winchip \& Petzold, 2016). Furthermore, developmental efficacy forecasts one's motivation and performance (Jacobsen \& Andersen, 2017). People with high self-efficacy persist and thrive in challenging situations (Goertzen \& Whitaker, 2015). Individuals with high developmental efficacy invest more effort in developmental activities (Reichard et al., 2016). Bandura (1982) argues that people with greater self-efficacy are motivated by obstacles and channel their energies to win, while people with low self-efficacy become too concerned with their failures and mishaps instead of seeking to win next time. People with high self-efficacy actively search for effective schemes to accomplish the task at hand, in this research the task at hand is leadership development. This study tested the hypothesis: developmental readiness does not affect leadership development.

\section{Research and Methodology}

The population $(\mathrm{N}=1,721)$ of study was MBA students within private universities in Kenya. The sample size of $\mathrm{n}=314$ was determined scientifically by Aiken (1997) formula. The study espoused stratified random sampling method. The developmental efficacy data was collected using a validated tool developed by Schwarzer and Jerusalem (1995). On the other hand, leadership development and demographic data was collected by tools developed through extensive review of relevant literature and validated through pilot study by the first researcher. In order to compare low and high score of developmental efficacy, the scores of developmental efficacy were divided into two groups by use of median. The analyses that were performed in this study included: correlation analysis, One-Way ANOVA and linear regression analysis. 


\section{Result and Discussion}

\section{Results}

A response rate of 92 percent (288) was obtained. The respondents aged 21-30 years were 53.47 percent (154), while 31-40 years were 34.72 percent (100) and 41-50 years were 11.81 percent (34). Male respondents were 51.39 percent (148), while female respondents were 48.61 percent (140). The results also revealed that 79.17 percent (228) of the respondents were employed/selfemployed at the time of data collection, while 15.28 percent (44) were employed/self-employed before but not at the time of data collection and only 5.56 percent (16) had never been employed/self-employed. The results showed that 62.5 percent (180) of the respondents were in managerial/leadership positions at the time of data collection, while only 37.5 percent (108) were not. Moreover, the respondents belonged to the following industries non-governmental organizations were 17.01 percent (49), government were 15.97 percent (46), corporate were 61.46 percent (177), while those who were not affiliated to any industry were 5.56 percent (16). Finally, 5.56 percent (16) of the respondents had never worked, 72.92 percent (210) had worked between $1-10$ years, and 18.01 percent (52) had worked between 11 - 20 years, while 3.47 percent (10) had worked for 21 years and above.

The results revealed that developmental efficacy is significantly correlated with leadership development, $\mathrm{r}(288)=.467, \mathrm{p}<.001$ as shown in table 1.

Table 1: Correlation between developmental efficacy and leadership development

\begin{tabular}{llll}
\hline & & Developmental Efficacy (DE) & Leadership Development (LD) \\
\hline DE & Pearson Correlation & 1 & $.423^{* *}$ \\
\cline { 2 - 4 } & Sig. (2-tailed) & .000 \\
\cline { 2 - 4 } & $\mathrm{N}$ & $.467^{* *}$ & 288 \\
\hline LD & Pearson Correlation & .000 & 1 \\
\cline { 2 - 4 } & Sig. (2-tailed) & 288 & 288 \\
\cline { 2 - 3 } & $\mathrm{N}$ & & \\
\hline
\end{tabular}

Source: Authors

While the outcome of One-Way ANOVA showed that respondents with low and high developmental efficacy had significantly different mean scores in leadership development, where $\mathrm{F}(1,286)=41.390, \mathrm{p}<.001$, as shown in table 2 .

Table 2: ANOVA of Leadership development with respect to developmental efficacy

\begin{tabular}{llllll}
\hline & Sum of Squares & df & Mean Square & F & Sig. \\
\hline Between Groups & 31.882 & 1 & 31.882 & 41.390 & .000 \\
\hline Within Groups & 220.304 & 286 & .770 & & \\
\hline Total & 252.186 & 287 & &
\end{tabular}

Source: Authors

With regard to demographic factors, the results of One-Way ANOVA revealed that the difference between groups' means of developmental efficacy with respect to employment status, position, industry, years of experience are statistically significant, $\mathrm{F}(2,285)=3.454, \mathrm{p}=.033, \mathrm{~F}(4,283)=2.567, \mathrm{p}=.038, \mathrm{~F}(3,284)=2.913, \mathrm{p}=.035, \mathrm{~F}(6,281)=2.313, \mathrm{p}=.038$ respectively. On the other hand, developmental efficacy group means with respect to age and gender are statistically insignificant. The results of linear regression revealed a significant model $\mathrm{F}(1,286)=79.803, \mathrm{p}<001$, as shown in table 3 and developmental efficacy accounts for 21.8 percent of the variations in leadership development, as depicted in table 4.

Table 3: ANOVA for regression of $L D$ against DE

\begin{tabular}{lllllll}
\hline Model & Sum of Squares & df & Mean Square & F & Sig. \\
\hline $\mathbf{1}$ & Regression & 55.017 & 1 & 55.017 & 79.803 & $.000 \mathrm{~b}$ \\
\cline { 2 - 7 } & Residual & 197.169 & 286 & .689 & & \\
\hline & Total & 252.186 & 287 & & & \\
\hline
\end{tabular}

a. Dependent Variable: LD

b. Predictors: (Constant), DE

Source: Authors 
Table 4: ANOVA for Regression of LD against DE

\begin{tabular}{|c|c|c|c|c|c|}
\hline Model & $\mathbf{R}$ & R Square & Adjusted R Square & Std. Error of the Estimate & Durbin-Watson \\
\hline 1 & $.467 \mathrm{a}$ & .218 & .215 & .83030 & 1.905 \\
\hline
\end{tabular}

Furthermore, developmental efficacy is a significant predictor of leadership development, $(\beta=.449, \mathrm{t}(286)=8.933, \mathrm{p}<.001)$, as shown in table 5 . The significance level of the study was $p<.05$, since the results revealed a $p<.001$, then the null hypothesis was rejected, while the alternative hypothesis was accepted, that is, developmental efficacy significantly affect leadership development.

Table 5: Coefficient for Regression of LD against DE

\begin{tabular}{lllllll}
\hline Model & & \multicolumn{2}{l}{$\begin{array}{l}\text { Unstandardized } \\
\text { Coefficients }\end{array}$} & Standardized Coefficients & t & Sig. \\
\cline { 3 - 6 } & & B & Std. Error & Beta & \\
\hline $\mathbf{1}$ & (Constant) & 1.523 & .178 & & 8.565 & .000 \\
\cline { 2 - 6 } & DE & .449 & .050 & .467 & 8.933 & .000 \\
\hline
\end{tabular}

Dependent Variable: LD

Source: Authors

\section{Discussion}

The present study sought to establish whether developmental efficacy had effect on leadership development. Correlation analysis, One-Way analysis of variances and regression analysis were conducted in furtherance of that objective. The correlation analysis revealed that developmental efficacy and leadership development were positively and significantly correlated, $\mathrm{r}(288)=.467, \mathrm{p}<$ .001. The findings are akin to Wigelsworth, Qualter \& Humphrey (2017) finding, who established that self-efficacy is related to academic attainment. The results imply that as the scores of developmental efficacy increase, the scores of leadership development also increase.

The One-Way ANOVA results revealed that respondents with low and those with high developmental efficacy had significantly different scores in leadership development, $\mathrm{F}(1,286)=41.390, \mathrm{p}<.001$. The results indicate that respondents with low developmental efficacy scores also have low leadership development scores and vice versa. Further, the results reveal the significance of developmental efficacy in boosting leadership capacity (Petridou, Nicolaidou and Karagiorgi, 2017).

Regression analysis reveals that developmental efficacy significantly affect leadership development, $F(1,286)=79.803$, $p<001$, and in addition, developmental efficacy accounts for $21.8 \%$ of the variations in leadership development. The study indicates that developmental efficacy scores forecasts the scores for leadership development $(\beta=.449, \mathrm{t}(286)=8.933, \mathrm{p}<.001)$. Similar findings were revealed in Wigelsworth et al.'s (2017) study, also comparable studies have yielded similar results, Petridou et al. (2017) established that self-efficacy was a significant predictor of performance, while Glowacki-Dudka, Murray, Gray and Johnson (2016) argued that self-efficacy greatly impacts one's development. Moreover, Phan (2012) revealed that self-efficacy significantly affects academic achievement. The results indicate that leadership development programs are more likely to benefit participants if they include developmental efficacy boosting content (Holmberg, Larsson \& Bäckström, 2016).

Given that the present study has established that developmental efficacy is both related and a predictor of leadership development, hence is important to establish whether different demographic groups differ in their scores of developmental efficacy. This knowledge is critical in endeavors to boost the developmental efficacy of leadership development participants. One-Way ANOVA revealed that the different age groups do not have significantly different mean scores in developmental efficacy, $\mathrm{F}(3,284)=.868, \mathrm{p}=.458$. The result indicate that age may not be a critical factor in designing and delivering developmental initiatives that is aimed at boosting potential leader's development efficacy.

The results also revealed that developmental efficacy mean scores of men and women are not significantly different, $\mathrm{F}(1,286)=.006$, $\mathrm{p}=.938$. The findings are in agreement with Kavussanu, Boardley, Jutkiewicz, Vincent and Ring's (2008) findings. Leadership developers, aiming to improve participants' developmental efficacy may not be required to deploy different tactics for different genders, as long as they are working with populations that have similar characteristics as the population in this study. However, the findings in different fields may differ with the findings in the present study, for example a study of the military in Canada revealed a significant difference between the self-efficacy of men and women (Wood \& Charbonneau, 2017). 
Furthermore, the results of One-Way ANOVA showed that respondents of different employment status had significantly different scores in developmental efficacy $\mathrm{F}(2,285)=3.454, \mathrm{p}=.033$. Respondents, who were employed at the time of the study, registered higher mean scores in developmental efficacy than their counterparts who were not employed. Employment offer people opportunities to exercise their confidence, this could be in form of solutions that employees may offer to solve a problem at work. When the suggested solution solves the intended problem, the employees' confidence in self grows further (Springer, 2016). Work also offer people opportunities to fail, which may also immunize the employees against the negative effects of failure and build their ability to recover quickly from such failure. The exposure to more challenging tasks at work may help in boosting the employees' ability to withstand challenges in life, including the challenges posed by leadership development. The results indicate that when it comes to developing leaders, the developer may vary the developmental initiatives, for those who are new in employment or have not been employed before may require remedies to boost their developmental efficacy before embarking full in leadership development. Additionally, the results of One-Way ANOVA revealed that respondents in different positions had significantly different scores in developmental efficacy, $\mathrm{F}(4,283)=2.567, \mathrm{p}=.038$. The respondents with higher positions also scored high in developmental efficacy and vice versa, the findings are similar to Dunbar et al.'s (2016) findings. Leadership demands confidence in one's ability, as one's managerial position increases, the more confidence is demanded from him or her. This may explain why rising in leadership position corresponds with higher developmental efficacy. Leaders in higher positions are likely to face many situations that may force them to learn how to recover quickly from failures and other difficulties they may face. Those situations increases leaders' developmental efficacy. Besides, the results of One-Way ANOVA revealed that respondents in different industries had significantly different developmental efficacy mean scores, $\mathrm{F}(3,284)=2.913, \mathrm{p}=.035$. The respondents who did not belong to any industry had the lowest mean score, followed by respondents in NGO, government and corporate, in that order. The results indicate that leadership development professionals should approach the improving of the learners' developmental efficacy with knowledge that learners from different industries may have different levels of developmental efficacy, hence they may require different developmental activities to boost learners' developmental efficacy.

Finally, One-Way ANOVA revealed that developmental efficacy mean scores are significantly different for respondents with different years of experience, $\mathrm{F}(5,282)=2.396, \mathrm{p}=.038$; the findings confirm Springer's (2016) conclusions that people's experience boosts their developmental efficacy. Work experience, like employment status or position, offers employees the opportunities to develop and demonstrate confidence in their abilities. It also offers people opportunities to fail and recover, hence build their resilience and at the same time, work may demand that employees withstand the many challenges that they face in the line of duty. These demands on the employees may explain why the longer the period they work the higher the developmental efficacy scores.

\section{Conclusions}

The results of the study revealed that developmental efficacy significantly affects leadership development. The study indicates that respondents who scored high in developmental efficacy also scored high in leadership development. The high scores in leadership development obtained by individuals with high learning goal orientation may be explained by the qualities that individuals with high developmental efficacy possess. They persist in the face of challenges, meaning that whatever demands that leadership development places on them, they are able to shoulder its weights. They exude confidence in their ability to learn leadership. They are resilient in the face of adversities and they believe that failure is a stepping stone not a hindrance. The study revealed that in improving/boosting leaders' developmental efficacy, one should take in consideration the participants' employment status, position, industry and years of experience, while age and gender of the participants may not matter. The study recommends that leadership development participants should be exposed to activities that boost their developmental efficacy alongside leadership development interventions, because developmental efficacy helps leadership learners to gain more from leadership development. The study further recommends a global study to examine the effect of developmental efficacy on leadership development, such a study will determine the universal applicability of the study findings.

\section{References}

Ardichvili, A., Dag, K., \& Manderscheid, S. (2016). Leadership development: Current and emerging models and practices. Advances in Developing Human Resources, Vol. 18, No. 3, pp. 275 - 285. https://doi.org/10.1177/1523422316645506

Asuga, G., Eacott, S., \& Scevak, J. (2015). School leadership preparation and development in Kenya: Evaluating performance impact and return on leadership development investment. International Journal of Educational Management, Vol. 29, No. 3, pp. 355-367. https://doi.org/10.1108/IJEM-10-2013-0158

Avolio, B., \& Hannah, S. (2009). Leader developmental readiness. Industrial and Organizational Psychology, Vol. 2, pp. 284 - 287. https://doi.org/10.1111/j.1754-9434.2009.01150.x

Avolio, B., \& Hannah, S. (2008). Developmental readiness: Accelerating leader development. Consulting Psychology Journal: Practice and Research, Vol. 60, No. 4, pp. 331 - 347. http://dx.doi.org/10.1037/1065-9293.60.4.331

Bandura, A. (1982). Self-efficacy mechanism in human agency. American Psychologist, Vol. 37, No. 2, pp. 122 - 147. http://dx.doi.org/10.1037/0003-066X.37.2.122

Beverborg, A., Sleegers, P., Endedijk, M., \& Veen, K. (2017). Towards sustaining levels of reflective learning: How do transformational leadership, task interdependence, and self-efficacy shape teacher learning in schools? In K. Leithwood et 
al. (eds.), How School Leaders Contribute to Student Success, Studies in Educational Leadership (pp. 93 - 129). Springer International Publishing AG. https://doi.org/10.1007/978-3-319-50980-8_6

Bong, M., \& Skaalvik, E. (2003). Academic Self-Concept and Self-Efficacy: How Different Are They Really? Educational Psychology Review, Vol. 15, No. 1, pp. 1 - 40. http://dx.doi.org/10.1023/A:1021302408382

DDI (2015). Ready-now leaders: 25 findings to meet tomorrow's business challenges - the global leadership forecast 2014-2015. https://www.ddiworld.com/DDI/media/trend-research/global-leadership-forecast-2014-2015_tr_ddi.pdf

Deloitte (2014). Global human capital trends: Engaging the $-\overline{2} 1$ st-century workforce. https://www2.deloitte.com/content/dam/Deloitte/ar/Documents/human-capital/arg_hc_global-human-capital-trends2014_09062014\%20(1).pdf

Dunbar, R., Dingel, M., Dame, L., Winchip, J., \& Petzold, A. (2016). Student social self-efficacy, leadership status, and academic performance in collaborative learning environments. Studies in Higher Education, $p p . \quad 1 \quad-\quad 18$. https://doi.org/10.1080/03075079.2016.1265496

Goertzen, B., \& Whitaker, B. (2015). Development of psychological capital in an academic-based leadership education program. Journal of Management Development, Vol. 34, No.7, pp. 773 - 786. Permanent link to this document: http://dx.doi.org/10.1108/JMD-07-2013-0100

Glowacki-Dudka, M., Murray, J., Gray, J., \& Johnson, S. (2016). Indiana women of achievement: using self-directedness, selfefficacy and self-determination to explore opportunities for leadership. International Journal of Lifelong Education, Vol. 35, No. 6, pp. 682 - 697. https://doi.org/10.1080/02601370.2016.1229696

Hannah, S., \& Avolio, B. (2010). Ready or not: How do we accelerate the developmental readiness of leaders? Journal of Organizational Behaviour, Vol. 31, pp. 1181 -1187. https://doi.org/10.1002/job.675

Holmberg, R., Larsson, M., \& Bäckström, M. (2016). Developing leadership skills and resilience in turbulent times: A quasiexperimental evaluation study. Journal of Management Development, Vol. 35, No. 2, pp. 154 - 169. https://doi.org/10.1108/JMD-09-2014-0093

Jacobsen, C., \& Andersen, L. (2017). Leading public service organizations: How to obtain high employee self-efficacy and organizational performance. Public Management Review, $\quad$ Vol. $19, \quad$ No. $2, \quad$ pp. $253 \quad-\quad 273$. https://doi.org/10.1080/14719037.2016.1153705

Kavussanu, M., Boardley, I., Jutkiewicz, N., Vincent, S., \& Ring, C. (2008). Coaching Efficacy and Coaching Effectiveness: Examining Their Predictors and Comparing Coaches' and Athletes' Reports. The Sport Psychologist, Vol. 22, pp. 383 - 404. https://research.birmingham.ac.uk/portal/files/2921806/Kavussanu2008.pdf

Mathooko, F., \& Ogutu, M. (2014).Coping strategies adopted by public universities in Kenya in response to environmental changes. Journal of Management and Strategy, Vol.5, No.1, pp. 93 - 107. https://doi.org/10.5430/jms.v5n1p93

Murphy, S., \& Johnson, S. (2016). Leadership and leader developmental self-efficacy: their role in enhancing leader development efforts. New Directions for Student Leadership, Vol. 149, pp. 73 - 84. https://doi.org/10.1002/yd.20163

Nah, C., \& Wan, K. (2010). Understanding developmental readiness. Retrieved September 13, 2016, from https://www.cscollege.gov.sg/knowledge/Pages/Understanding-Developmental-Readiness.aspx

Petridou, A., Nicolaidou, M., \& Karagiorgi, Y. (2017). Exploring the impact of professional development and professional practice on school leaders' self-efficacy: a quasi-experimental study. School Effectiveness and School Improvement, Vol. 28, No. 1, pp. 56 - 73. https://doi.org/10.1080/09243453.2016.1236734

Phan, H (2012). Relations between informational sources, self-efficacy and academic achievement: a developmental approach. Educational Psychology, Vol. 32, No. 1, pp. 81-105. https://doi.org/10.1080/01443410.2011.625612

Reichard, R., \& Walker, D. (2016). In pursuit: Mastering leadership through leader developmental readiness. New Directions for Student Leadership, Vol. 149, pp. 15 - 25. https://doi.org/10.1002/yd.20158

Reichard, R., Walker, D., Putter, S., Middleton, E., \& Johnson, S. (2016). Believing is becoming: The role of leader developmental efficacy in leader self-development. Journal of Leadership \& Organizational Studies, $p p . \quad 1 \quad-\quad 20$. https://doi.org/10.1177/1548051816657981

Schwarzer, R., \& Jerusalem, M. (1995). Generalized self-efficacy scale. In J. Weinman, S. Wright, \& M. Johnston, measures in health psychology: A user's portfolio. Causal and control beliefs (pp. 35 - 37). Windsor, UK: NFER-NELSON. https://www.drugsandalcohol.ie/26768/1/General_Self-Efficacy_Scale\%20(GSE).pdf

Snook, S., Nohria, N., \& Khurana, R. (2012). The handbook for teaching leadership: Knowing, doing and being. Los Angeles, CA: Sage.

Springer, S. (2016). Examining predictors of group leader self-efficacy for preservice school counselors. The Journal for Specialists in Group Work, Vol. 41, No. 4, pp. 286-311. https://doi.org/10.1080/01933922.2016.1228723

UNC (2014). UNC leadership survey 2014: How to accelerate leadership development. http://docplayer.net/17989371-Uncleadership-survey-2014-how-to-accelerate-leadership-development.html

Wigelsworth, M., Qualter, P., \& Humphrey, N. (2017). Emotional self-efficacy, conduct problems, and academic attainment: Developmental cascade effects in early adolescence. European Journal of Developmental Psychology, Vol. 14, No. 2, pp. 172 - 189. https://doi.org/10.1080/17405629.2016.1180971

Wood, V., \& Charbonneau, D., (2017). Gender, self-efficacy, and warrior identification in Canadian Army personnel. Journal of Gender Studies, pp. 1 - 13. https://doi.org/10.1080/09589236.2017.1301812 